S. Gadau · C. Emanueli · S. Van Linthout · G. Graiani •

M. Todaro · M. Meloni - I. Campesi · G. Invernici ·

F. Spillmann $\cdot$ K. Ward $\cdot$ P. Madeddu

\title{
Benfotiamine accelerates the healing of ischaemic diabetic limbs in mice through protein kinase B/Akt-mediated potentiation of angiogenesis and inhibition of apoptosis
}

Received: 11 April 2005 / Accepted: 6 October 2005 / Published online: 17 January 2006

C) Springer-Verlag 2006

\begin{abstract}
Aims/hypothesis: Benfotiamine, a vitamin B1 analogue, reportedly prevents diabetic microangiopathy. The aim of this study was to evaluate whether benfotiamine is of benefit in reparative neovascularisation using a type I diabetes model of hindlimb ischaemia. We also investigated the involvement of protein kinase $B$ (PKB)/Akt in the therapeutic effects of benfotiamine. Methods: Streptozotocin-induced diabetic mice, given oral benfotiamine or vehicle, were subjected to unilateral limb ischaemia. Reparative neovascularisation was analysed by histology. The expression of Nos 3 and Casp3 was evaluated by real-time PCR, and the activation state of PKB/Akt was assessed by western blot analysis and immunohistochemistry. The functional importance of $\mathrm{PKB} / \mathrm{Akt}$ in benfotiamine-induced effects
\end{abstract}

S. Gadau $\cdot$ S. Van Linthout $\cdot$ F. Spillmann ·

K. Ward · P. Madeddu

Experimental Medicine and Gene Therapy,

National Institute of Biostructures and Biosystems (INBB),

Osilo, Italy

C. Emanueli · G. Graiani · M. Meloni · I. Campesi

Molecular and Cellular Medicine,

National Institute of Biostructures and Biosystems (INBB),

Alghero, Italy

C. Emanueli · P. Madeddu $(\square)$

Experimental Cardiovascular Medicine,

Bristol Heart Institute,

University of Bristol, Bristol BS2 8HW, UK

e-mail: madeddu@yahoo.com

Tel: +44-117-9283145

Fax: +44-117-9283581

M. Todaro

Cellular and Molecular Pathophysiology Laboratory,

University of Palermo, Palermo, Italy

G. Invernici

Besta Neurological Institute, Milan, Italy

P. Madeddu

Multimedica Research Institute, Milan, Italy was investigated using a dominant-negative construct. Results: Diabetic muscles showed reduced transketolase activity, which was corrected by benfotiamine. Importantly, benfotiamine prevented ischaemia-induced toe necrosis, improved hindlimb perfusion and oxygenation, and restored endothelium-dependent vasodilation. Histological studies revealed the improvement of reparative neovascularisation and the inhibition of endothelial and skeletal muscle cell apoptosis. In addition, benfotiamine prevented the vascular accumulation of advanced glycation end products and the induction of pro-apoptotic caspase-3, while restoring proper expression of Nos 3 and Akt in ischaemic muscles. The benefits of benfotiamine were nullified by dominant-negative PKB/Akt. In vitro, benfotiamine stimulated the proliferation of human EPCs, while inhibiting apoptosis induced by high glucose. In diabetic mice, the number of circulating EPCs was reduced, with the deficit being corrected by benfotiamine. Conclusions/ interpretation: We have demonstrated, for the first time, that benfotiamine aids the post-ischaemic healing of diabetic animals via $\mathrm{PKB} / \mathrm{Akt}$-mediated potentiation of angiogenesis and inhibition of apoptosis. In addition, benfotiamine combats the diabetes-induced deficit in endothelial progenitor cells.

Keywords Advanced glycation end-products - AGEs . Angiogenesis · Apoptosis - Benfotiamine - Caspase · Diabetes $\cdot$ Endothelial progenitor cells $\cdot$ Ischaemia Vitamin B1

Abbreviations Ad.DN-PKB/Akt: adenoviral vector carrying the dominant-negative $\mathrm{Akt}_{308 / 547}$ - Ad.luc: adenoviral vector carrying the gene encoding luciferase eNOS: endothelial nitric oxide synthase - EPC: endothelial progenitor cell - GSH: reduced glutathione - GSSG: oixidized glutathione $\cdot \mathrm{NF}-\mathrm{KB}$ : nuclear factor- $\mathrm{KB} \cdot \mathrm{PKB}$ : protein kinase $\mathrm{B} \cdot \mathrm{PKC}$ : protein kinase $\mathrm{C} \cdot \mathrm{ROS}$ : reactive oxygen species - STZ: streptozotocin - TPP: thiamine pyrophosphate $\cdot$ TUNEL: terminal deoxynucleotidyl transferase-mediated dUTP nick end-labelling 


\section{Introduction}

Peripheral arterial obstructive disease represents a major health problem in developed countries [1,2]. Critical limb ischaemia is ten times more common in diabetic patients than in non-diabetic people, and is frequently associated with non-healing ulcers and gangrene [3-5]. Recently, new hope has been provided by therapeutic angiogenesis, a novel strategy aimed at fostering collateralisation of ischaemic tissues by means of vascular growth factor supplementation [6-8]. However, clinical efficacy might be diminished by the negative impact of metabolic disorders and risk factors on resident endothelial cells [9-11].

Epidemiological studies have shown a strong relationship between hyperglycaemia-induced oxidative stress and microvascular/macrovascular complications in both types of diabetes [12-14]. Excessive production of reactive oxygen species (ROS) by NAD(P)H oxidase [15-17] and the mitochondrial electron transport chain [18] jeopardises reparative vascular growth and may be involved in destabilising the existing microvasculature via stimulation of apoptosis $[6,8]$. ROS inhibit the glycolytic enzyme glyceraldehyde phosphate dehydrogenase and hence lead to triosephosphate metabolite accumulation, responsible for the activation of the diacylglycerol-protein kinase C (PKC), hexosamine and polyol pathways [18]. These mechanisms, together with an increase in AGEs, induce vascular damage by disturbing protein and matrix integrin functions, activating the proinflammatory transcription factor nuclear factor- $\mathrm{KB}(\mathrm{NF}-\mathrm{kB})$, ultimately amplifying ROS formation [19-21]. Furthermore, hyperglycaemia inhibits endothelial nitric oxide synthase (eNOS) through post-translational modification at the protein kinase B (PKB)/Akt site [22] and oxidation of eNOS cofactor tetrahydrobiopterin [23], thereby altering a pathway that, under normal circumstances, operates as a pro-survival and pro-angiogenic, signalling downstream to various growth factors and cytokines [24-26]. There are at least other two mechanisms by which hyperglycaemia may affect reparative neovascularisation: the glycation/inactivation of fibroblast growth factor 2 [20] and the impairment of endothelial progenitor cell (EPC) survival and migration through inhibition of phosphorylation of PKB/Akt and eNOS [27]. Therefore, advancement in therapeutic angiogenesis may require the use of agents obviating the deficit in PKB/Akt activity [28] and NO availability [23].

Thiamine pyrophosphate (TPP) is the cofactor for transketolase, the rate-limiting enzyme that shunts glyceraldehyde 3-phosphate and fructose 6-phosphate from glycolysis into the non-oxidative branch of the pentose phosphate pathway. Thiamine deficiency has been reported in diabetes [29], and correction of the defect by supplementation of thiamine or its derivative, benfotiamine ( $S$ benzoylthiamine- $O$-monophosphate), was shown to protect against diabetic nephropathy [29] and retinal microangiopathy [30]. These results were associated with activation of transketolase inhibition of PKC and inhibition of AGE and hexosamine formation, in spite of persistently elevated plasma glucose levels. The partition coefficient of benfotiamine (similar to that of thiamine) indicates that it is not lipophilic. Moreover, pharmacokinetic studies indicate that the major form of thiamine delivered by benfotiamine is $S$-benzoylthiamine, which is lipophilic (i.e. has a high partition coefficient) [31, 32].

The aim of the present study was to test the novel hypothesis that benfotiamine supplements would benefit the post-ischaemic healing of type I diabetic mice, through restoration of proper reparative angiogenesis/vasculogenesis and inhibition of vascular apoptosis. Furthermore, the molecular and cellular mechanisms implicated in the therapeutic action of benfotiamine were investigated.

\section{Materials and methods}

\section{Diabetes induction}

All procedures were carried out in accordance with the Guide for the Care and Use of Laboratory Animals (1996; Institute of Laboratory Animal Resources, National Academy of Sciences, Bethesda, MD, USA) and European legislation (as stated on http://europa.eu.int/comm/research/ science-society/ethics/ethics_en.html). Diabetes was induced in male CD1 mice (Charles River, Comerio, Italy) by injection of streptozotocin (STZ; $40 \mathrm{mg} / \mathrm{kg}$ body weight i.p. per day for 5 days; Sigma, Milan, Italy) [8].

\section{Benfotiamine supplementation}

At 2 weeks after diabetes induction, mice (aged 12 weeks) were randomly assigned to receive benfotiamine $(80 \mathrm{mg} / \mathrm{kg}$ body weight per day, Sigma) or vehicle $(1 \mathrm{mmol} / \mathrm{l} \mathrm{HCl})$ in drinking water.

Ischaemia induction

At 2 weeks after treatment randomisation, unilateral limb ischaemia was surgically induced with mice under anaesthesia (2,2,2-tribromoethanol, $880 \mathrm{mmol} / \mathrm{kg}$ body weight i.p., Sigma), as described previously [8].

\section{Post-ischaemic recovery}

A clinical score was calculated (in $n=18-21$ mice per group), based on the number of necrotic toes and occurrence of foot auto-amputation. Mice showing complete limb salvage scored zero. One point was given for each necrotic toe. Five points were given to mice with all toes necrotic or foot amputation.

In conscious mice, systolic blood pressure and heart rate were measured by tail-cuff plethysmography (Visitech Systems, Apex, NC, USA) [33]. Limb blood-flow recovery was assessed by laser Doppler flowmetry (Perimed, 
Järfälla, Stockholm, Sweden) [34], and the OxyLite/ OxyFlo probe (Oxford Optronix, Oxford, UK) in 9-14 mice per group. In addition, the effect of benfotiamine on endothelium-dependent vasodilation was assessed by evaluating the response to intravenous injection of graded doses of acetylcholine $(40-4,000 \mathrm{nmol} / \mathrm{kg}$ body weight, Sigma). Vascular conductance was calculated according to the following formula: muscular blood-flow / mean blood pressure.

\section{Quantification of neovascularisation and apoptosis}

Capillary and myofibre density was determined in transverse muscular sections ( $n=9-12$ per group), as described previously [34]. Apoptosis of endothelial cells and myocytes was assessed by the terminal deoxynucleotidyl transferase-mediated dUTP nick end-labelling (TUNEL) assay, as described previously [8].

To elucidate the functional role of $\mathrm{PKB} / \mathrm{Akt}$ in the vascular effects induced by benfotiamine, a separate experiment with adenoviral vector carrying the dominantnegative $\mathrm{Akt}_{308 / 547}$ (Ad.DN-PKB/Akt) was performed [34, 35]. Limb adductor muscles of benfotiamine-treated mice were injected with Ad.DN-PKB/Akt or the adenovirus containing the gene encoding luciferase (Ad.Luc) (each at $5 \times 10^{7}$ plaque forming units, $n=8$ per group) at the time of ischaemia induction. Animals were killed 2 weeks later for evaluation of reparative neovascularisation.

\section{Immunohistochemical identification of AGEs}

At 2 weeks from ischaemia, the carotid arteries were harvested from anaesthetised diabetic (benfotiamine- or vehicle-treated) or non-diabetic mice ( $n=4$ per group). Vessels were fixed and embedded in paraffin. Immunohistochemical identification of AGEs was carried out as described previously $[36,37]$. The number of AGE-positive endothelial cells in six consecutive sections was averaged, and the average number for each vessel was then used to calculate the mean value for each group, which was expressed as the number of AGE-positive endothelial cells per section.

Spectrophotometric assay of transketolase activity

The activity of the TPP-dependent enzyme transketolase was measured in hindlimb skeletal muscles ( $n=6$ mice per group) by the kinetic method of Chamberlain et al. [38].

Evaluation of gene expression

Quantification of Vegfa, Nos 3 and Casp 3 mRNA levels

Real-time quantitative PCR (ABI PRISM 7000 Sequence Detection System Software, version 1.0; Perkin Elmer,
Boston, MA, USA) was used to determine the vascular endothelial growth factor-A (Vegfa), Nos3, Casp3 and Rpl32 mRNA content in limb adductors obtained at 3 days after ischaemia induction ( $n=5-10$ per group). The sequences of the primers targetting murine Vegfa and Nos 3 have previously been published [39]. The sequences of the primers used to target Casp3 were as follows: forward: 5'AGCTGTACGCGCACAAGCTA-3'; reverse: 5'-CCGTT GCCACCTTCCTGTTA-3'. The primers used to target Rpl32 had the following sequences: forward: 5'-TGCCCACGGAG GA CTGACA-3'; reverse: 5'-AGGTG CTGGGAGCTGC TACA-3'. Expression levels were normalised to levels of Rpl32 (housekeeping gene that encodes ribosomal protein L32) cDNA.

\section{Western blot analysis of activated caspase-3}

Analyses were performed on homogenates of muscles $(n=6$ per group) harvested at 3 days from ischaemia, as described previously [39]. Western blot analysis of PKB/Akt was performed using primary antibodies raised against total or forms of the kinase phosphorylated on Ser473 (Cell Signaling Technology, Lake Placid, NY, USA). Activated caspase-3 was detected using a rabbit monoclonal antibody (Cell Signaling) that recognises the large fragment $(17 / 19 \mathrm{kDa})$ resulting from cleavage adjacent to Asp175.

\section{Immunohistochemistry of Ser473-phosphorylated PKB/Akt}

The analysis of phosphorylated $\mathrm{PKB} / \mathrm{Akt}$ was performed on freshly isolated HUVECs, plated on gelatin coverslips at a density of 10,000 per coverslip, using mouse monoclonal antibody IgG2b (catalogue no. 4051; Cell Signaling). Fol-

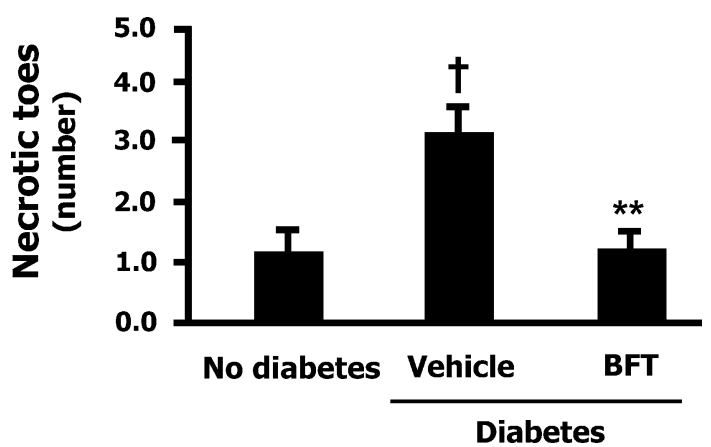

Fig. 1 Benfotiamine improves the clinical outcome of STZ-induced diabetic mice subjected to unilateral limb ischaemia induced by surgery. The bar graph shows the ischaemic score of diabetic and non-diabetic mice subjected to surgical interruption of femoral blood-flow. At 2 weeks after induction of diabetes by STZ, mice were randomly assigned to receive benfotiamine (BFT, $80 \mathrm{mg} / \mathrm{kg}$ body weight per day, $n=20$ ) or vehicle in drinking water (vehicle, $n=21$ ). Two weeks after initiation of treatment, unilateral limb ischaemia was induced by surgical interruption of the left femoral artery. The clinical score was determined at the end of a 2-week recovery period. Non-diabetic mice $(n=18)$ are shown for reference. Values are means \pm SEM. ${ }^{\dagger} p<0.01$ vs non-diabetic mice, ${ }^{* *} p<0.01$ vs vehicle-treated diabetic mice 
lowing exposure to primary antibody, cells were treated with fluorescein-conjugated anti-mouse antibodies (Invitrogen, Carlsbad, CA, USA). Counterstaining of cells was performed using Hoechst 33342.

Immunohistochemistry studies were performed on paraffin-embedded sections of adductor muscle $(n=3$ per group, $5 \mu \mathrm{m}$ in thickness) using the biotinylated primary

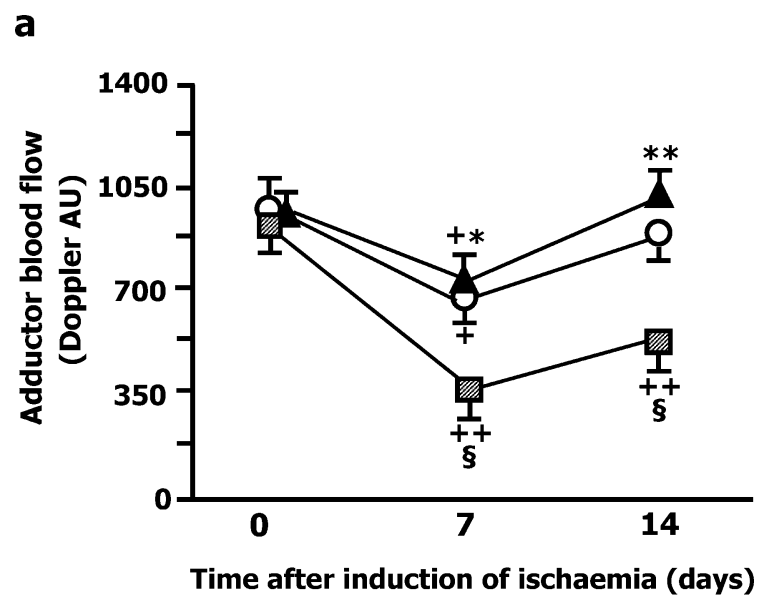

b

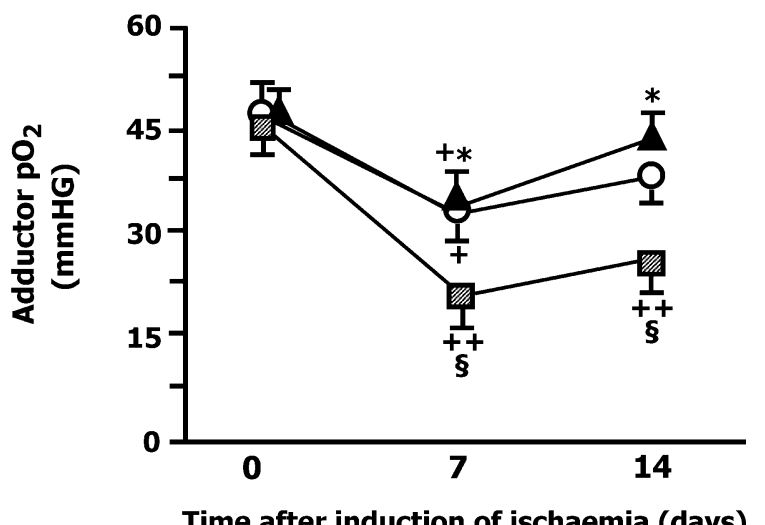

Time after induction of ischaemia (days)

C

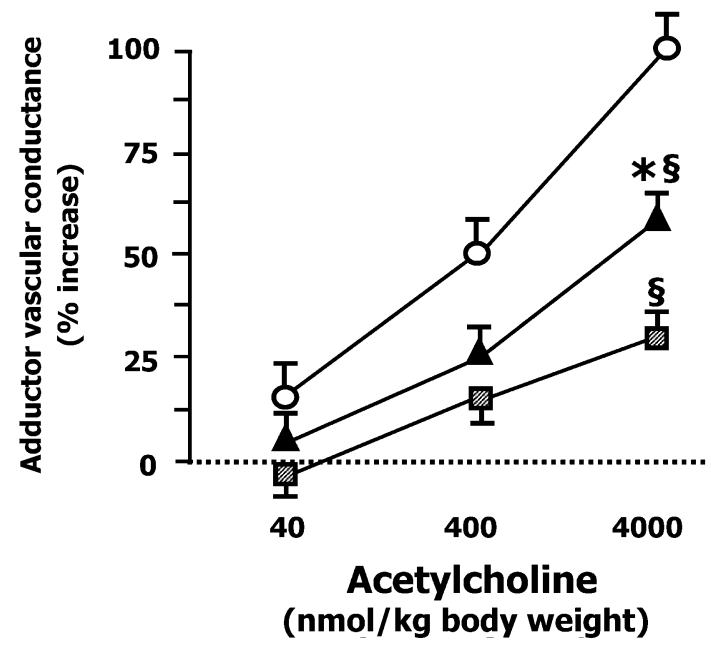

antibody Phosphorylated-Akt (Ser 473, mouse IgG2b monoclonal antibody, 4051; Cell Signaling). Staining was detected using 3-amino-9-ethylcarbazole as the colorimetric substrate. Counterstaining of tissue sections was performed using aqueous haematoxylin.

\section{Quantification of NO metabolites and glutathione}

NO metabolites were measured in muscles obtained at 3 days after ischaemia ( $n=9$ per group) using a colorimetric non-enzymatic assay (Invitrogen).

The aortic concentration of reduced glutathione (GSH) and oxidised glutathione (GSSG) was determined in the same mice as above by using a colorimetric assay (Oxis Research, Portland, OR, USA).

In vitro proliferation and apoptosis assays on human EPCs

Human EPCs were selected from circulating mononuclear cells of healthy volunteers, as described previously [40, 41]. EPCs were stimulated for 3 days with fresh culture medium containing normal or high glucose, $2 \%$ or $5 \%$ serum, plus benfotiamine $(50,100$ and $150 \mu \mathrm{mol} / \mathrm{l})$ or vehicle. Proliferation was then measured by the $3-(4,5-$ dimethylthiazol-2-yl)-5-(3-carboxymethoxyphenyl)-2-(4sulfophenyl)-2H-tetrazolium inner salt (MTS) assay (Promega, Madison, WI, USA). Each experiment was performed in triplicate and repeated three times.

The apoptosis assay was performed on human EPCs after challenge with high glucose and $2 \%$ serum in the presence of benfotiamine $(150 \mu \mathrm{mol} / \mathrm{l})$ or vehicle. In control experiments, EPCs were maintained under normal glucose and 5\% serum. Each condition was tested in ten wells using the same pool of cells.

Fig. 2 Benfotiamine improves the perfusion and oxygenation of diabetic adductor muscles subjected to surgical induction of unilateral limb ischaemia. a Blood-flow of left adductor muscles as measured by the OxyLite/OxyFlo probe before, and 7 and 14 days after ischaemia induction ( $n=9-14$ mice per group). Benfotiaminetreated diabetic mice (filled triangles) showed improved perfusion of the ischaemic adductor, as compared with vehicle-treated diabetic animals (hatched squares), thus restoring the physiological recovery observed in non-diabetic animals (open circles). b Oxygenation of adductor muscles as measured with the OxyLite/OxyFlo probe. Benfotiamine-treated diabetic mice showed increased muscular $\mathrm{PO}_{2}$, as compared with vehicle-treated mice. c Adductor vasodilator response to intravenous bolus injection of acetylcholine (40-4,000 ng/ $\mathrm{kg}$ body weight). Vasodilator response was depressed in vehicletreated diabetic mice, with this deficit partially compensated by benfotiamine treatment $(n=4-5$ mice per group). All values are means \pm SEM. ${ }^{+} p<0.05$ and ${ }^{++} p<0.01$ vs day $0,{ }^{\S} p<0.05$ vs nondiabetic mice, ${ }^{*} p<0.05$ and $* * p<0.01$ vs vehicle-treated diabetic mice 
Assessment of circulating EPC number

At 3 days from ischaemia, peripheral blood mononuclear cells were isolated from $500 \mu$ l of blood by density-gradient centrifugation with Histopaque 1083 (Sigma). Four days after EPC culture on rat vibronectin, EPCs were assayed by co-staining with fluorescent-labelled acetylated LDL (DilAcLDL) (Biomedical Technologies) and FITC-conjugated Bandeiraea simplicifolia lectin I (Vector Laboratories). Fluorescent microscopy identified double-positive cells as EPCs, which were automatically counted in six randomly selected power fields captured (at $\times 100)$.

Statistical analysis

All results are expressed as means \pm SEM. Analyses were performed by using SigmaStat, version 3.1(Systat, Point
Richmond, CA, USA). One-way ANOVA tested for treatment effect. The Holm-Sidak test was then used for pairwise comparisons and comparisons vs controls. A $p$ value of less than 0.05 was considered statistically significant.

\section{Results}

Body weight and systemic haemodynamics

Systolic blood pressure, heart rate and body weight were similar among diabetic and non-diabetic mice before and after ischaemia induction, with no significant effect of benfotiamine (data not shown). Consistent with other reports [29, 30], benfotiamine did not influence hyperglycaemia or glycosuria (data not shown).

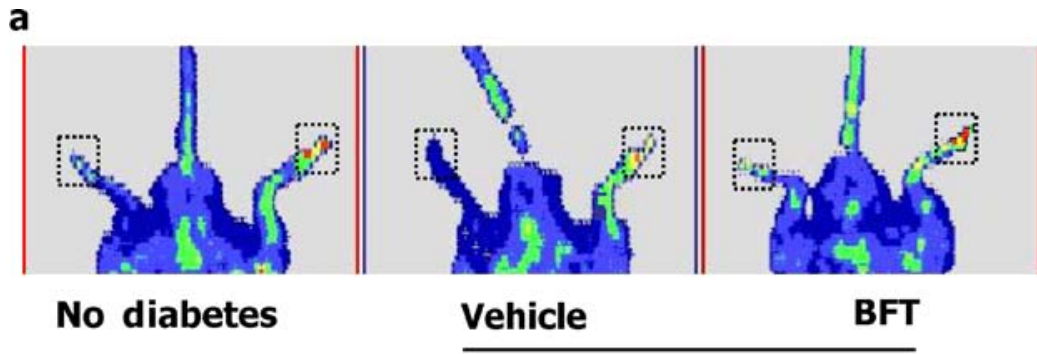

Diabetes

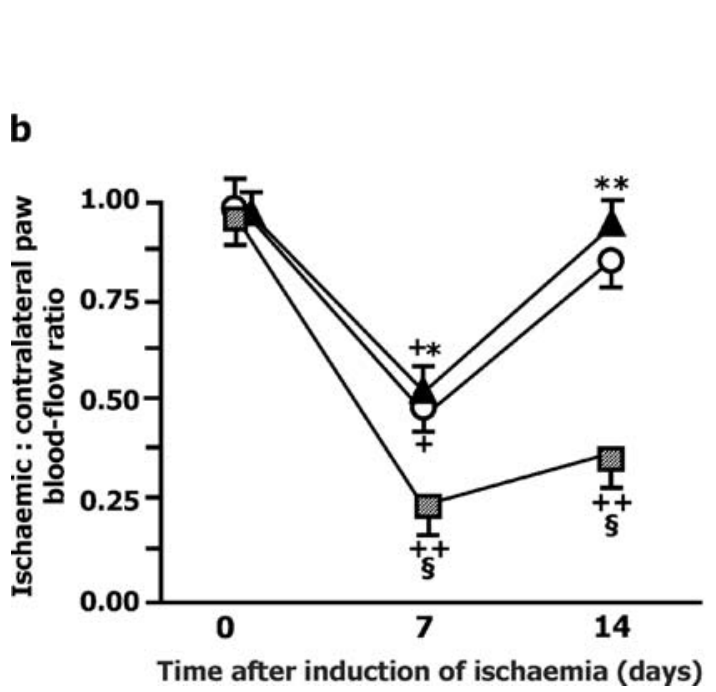

Fig. 3 Benfotiamine improves the cutaneous blood flow to the distal extremity of diabetic limbs submitted to operative ischaemia. a Photographs show typical laser Doppler images of skin blood flow captured from diabetic (given vehicle or benfotiamine [BFT]) and non-diabetic mice at 7 days after induction of ischaemia. The dotted squares include the area of interest, where cutaneous perfusion was calculated to determine the ischaemic:contralateral ratio. Colour scale from blue to brown indicates progressive increases in blood flow. b The ischaemic:contralateral blood flow ratio at the level of the left paw as measured by the laser Doppler flowmetry before, and 7 and 14 days after the induction of ischaemia. Benfotiamine-treated diabetic mice (filled triangles) showed improved perfusion of the ischaemic paw, as compared with vehicle-treated diabetic animals (hatched squares), and had ratios similar to those observed for nondiabetic controls (open circles). Values are means \pm SEM; $n=12-14$ mice per group. ${ }^{+} p<0.05$ and ${ }^{++} p<0.01$ vs day $0,{ }^{\S} p<0.05$ vs nondiabetic mice, $* p<0.05$ and $* * p<0.01$ vs vehicle-treated diabetic mice 
Benfotiamine improves the clinical outcome and haemodynamic recovery of diabetic mice

As illustrated in Fig. 1, the mean number of necrotic toes was higher among the diabetic mice than among the control animals $(p<0.01)$. Among the diabetic mice, benfotiamine improved the clinical outcome ( $p<0.01$ vs vehicle) such that the mean number of necrotic toes among this subgroup was similar to that observed for the untreated non-diabetic animals $(p=\mathrm{NS})$.

Figure $2 \mathrm{a}$ shows the results obtained by measuring adductor blood-flow using the intramuscular OxyLite/ OxyFlo probe (9-14 mice per group). At 7 days after surgery, a deficit in perfusion was detected in all groups, although ischaemia was more profound in adductors of vehicle-treated diabetic mice $(p<0.05$ vs benfotiaminetreated diabetic and non-diabetic animals). At 14 days, there was a clear difference between benfotiamine and vehicle, with the former leading to complete haemodynamic recovery, and diabetic mice given the latter showing persistently low perfusion ( $p<0.01$ vs benfotiamine). The overall recovery of benfotiamine-treated diabetic mice was similar to that of non-diabetic control animals. Figure $2 b$ indicates delayed oxygenation recovery in vehicle-treated diabetic mice, as compared with control mice, with this deficit being abrogated by benfotiamine.

In separate experiments, the vasodilation response to acetylcholine was measured at 14 days after ischaemia. The conductance response curve to acetylcholine for untreated diabetic animals was shifted to the right when compared a
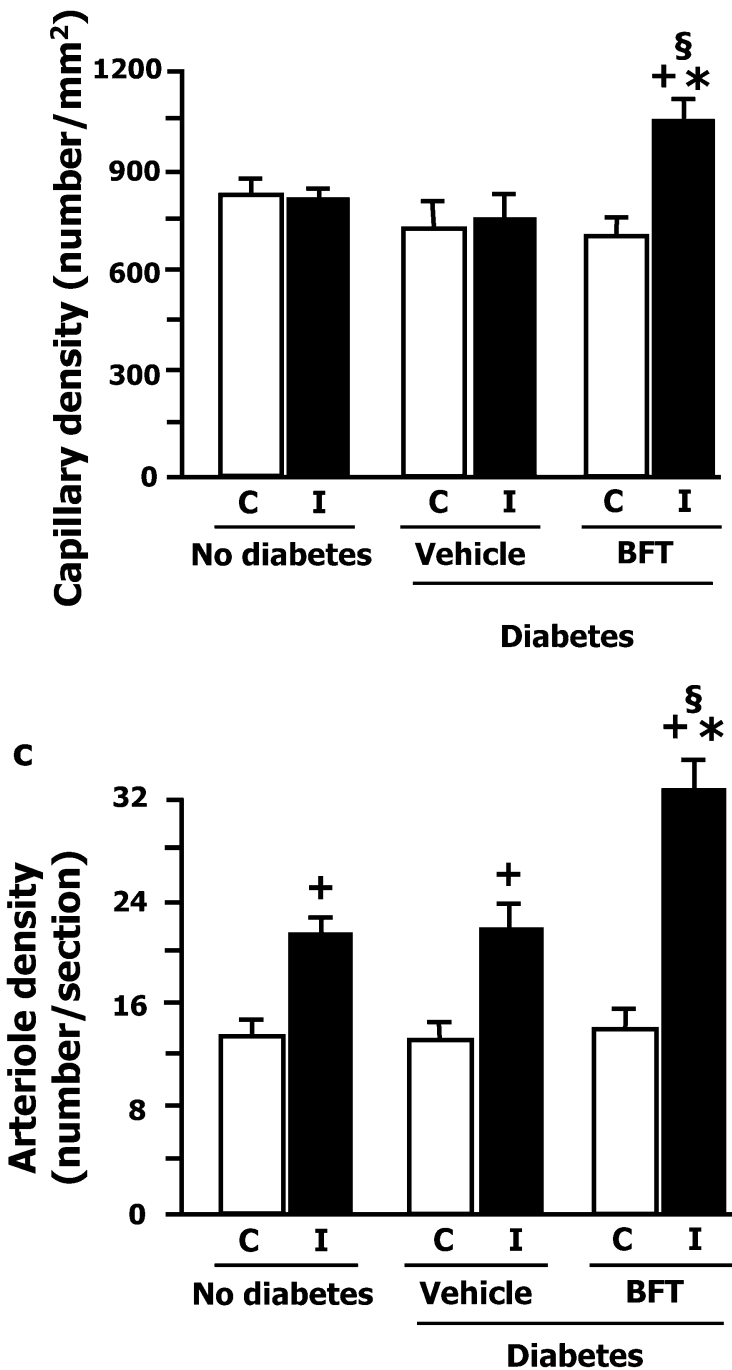

Fig. 4 Benfotiamine improves reparative neovascularisation response to ischaemia in diabetic mice. a Capillary density of ischaemic $(I)$ or non-ischaemic contralateral $(C)$ adductor muscles harvested from diabetic or non-diabetic mice at 14 days after surgery. Benfotiamine stimulates the capillarisation of ischaemic diabetic muscles. b Results expressed as ratio of capillary:myofibre density. $\mathbf{c}$ The increase in arteriole density produced by induction of

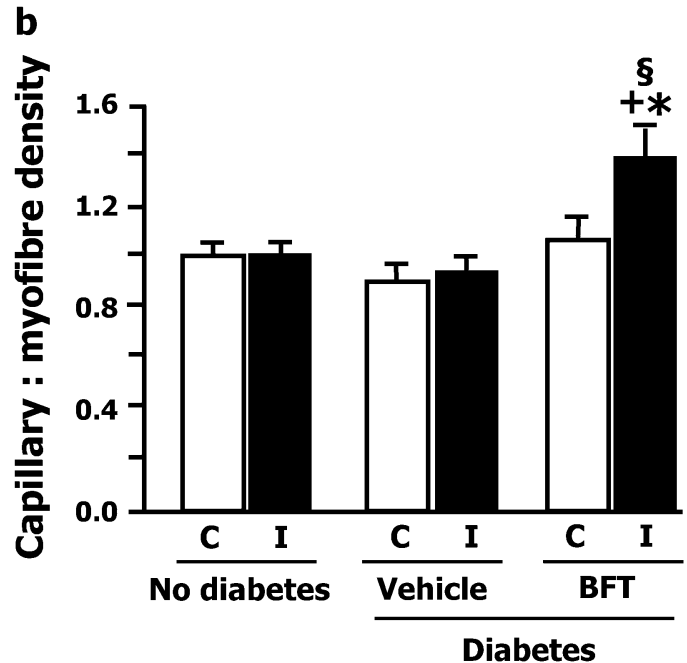

d

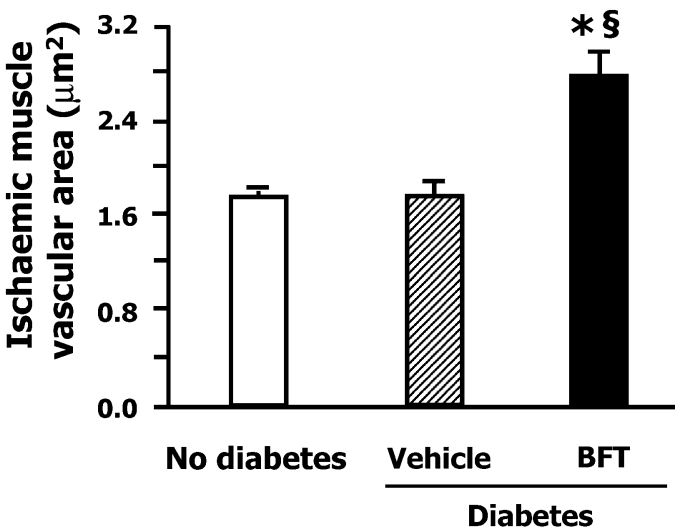

ischaemia in adductor muscles. Arteriogenesis was potentiated by benfotiamine in ischaemic diabetic muscles. d The increase in the vascular area of ischaemic muscles harvested form benfotiaminetreated diabetic mice. Values are means \pm SEM; $n=9-12$ mice per group. ${ }^{+} p<0.05$ vs contralateral muscle, ${ }^{\S} p<0.05$ vs non-diabetic mice, ${ }^{*} p<0.05$ vs vehicle-treated diabetic mice. BFT Benfotiamine 
with that for non-diabetic animals (Fig. 2c, $n=4-5$ per group). Benfotiamine partially restored endothelium-dependent vasodilation.

Figure 3a illustrates typical laser Doppler images of superficial limb blood flow in diabetic and non-diabetic mice at 1 week after ischaemia. As indicated in Fig. 3b, untreated diabetic mice showed a persistently reduced Doppler perfusion ratio over time $(n=12, p<0.01$ vs day 0$)$. The defect was abrogated by benfotiamine, with complete recovery of blood flow in the operated muscle $(n=14$, $p=\mathrm{NS}$ vs contralateral), thus matching the trend observed over time in non-diabetic control animals.

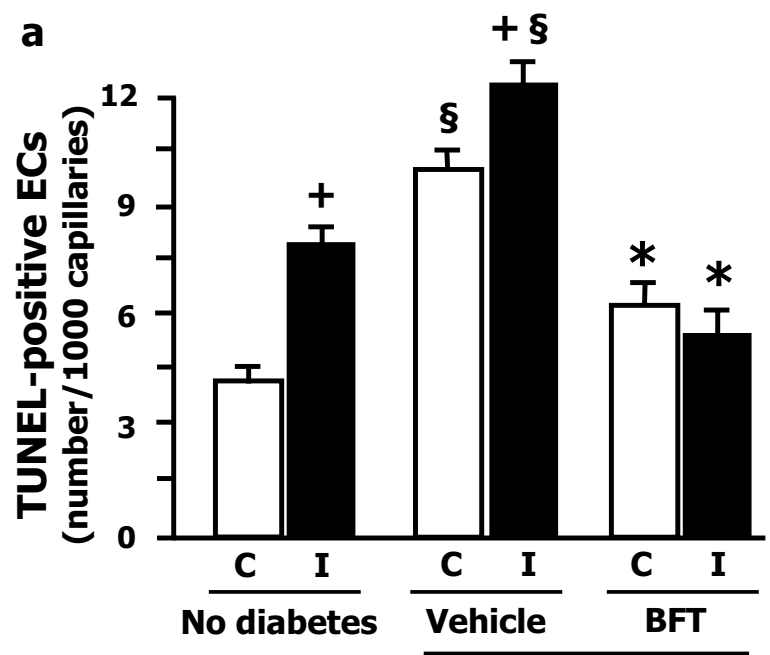

Diabetes

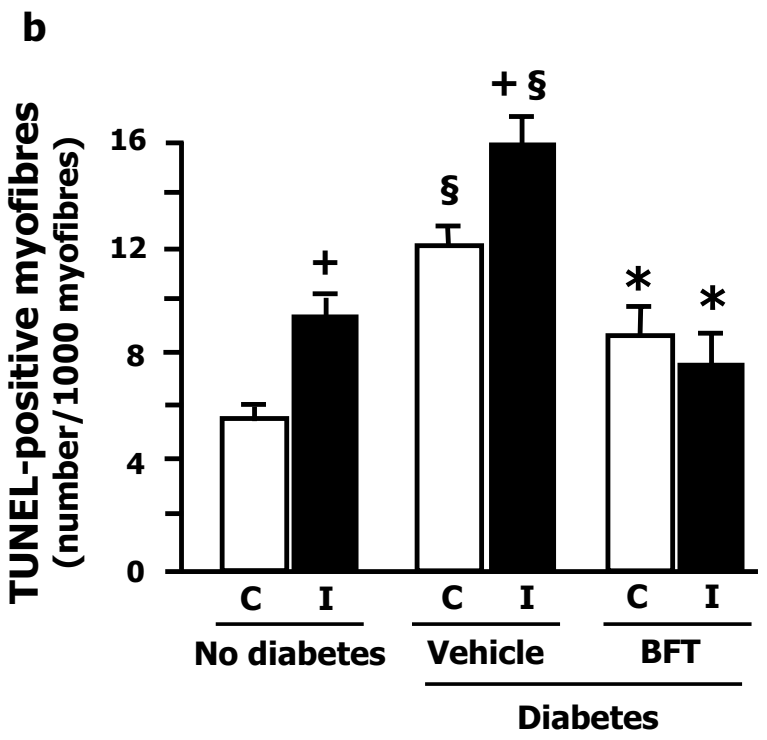

Fig. 5 Benfotiamine protects endothelial and skeletal muscle cells from apoptosis. a The bar graph shows that endothelial cell $(E C)$ apoptosis is strikingly increased in ischaemic $(I)$ and non-ischaemic contralateral $(C)$ adductor muscles harvested from vehicle-treated diabetic mice. Benfotiamine (BFT) reduced apoptosis bilaterally, leading to complete abrogation of ischaemia-induced cell death. $\mathbf{b}$ The bar graph shows the results observed at the myofibre level, where
Benfotiamine enhances reparative neovascularisation in diabetic mice

At 14 days, reparative neovascularisation was evident in ischaemic muscles of non-diabetic mice, as indicated by increases in arteriole number and vascular area (Fig. 4c,d), whereas capillary density was similar in ischaemic and contralateral muscles (Fig. 4a,b). There was no significant difference in the neovascularisation of vehicle-treated diabetic mice, as compared with that of the non-diabetic control mice ( $p=\mathrm{NS}$ ), but, importantly, the neoangiogenesis response was insufficient to ensure proper haemodynamic recovery in the diabetic animals (see above), thus indicat-
C
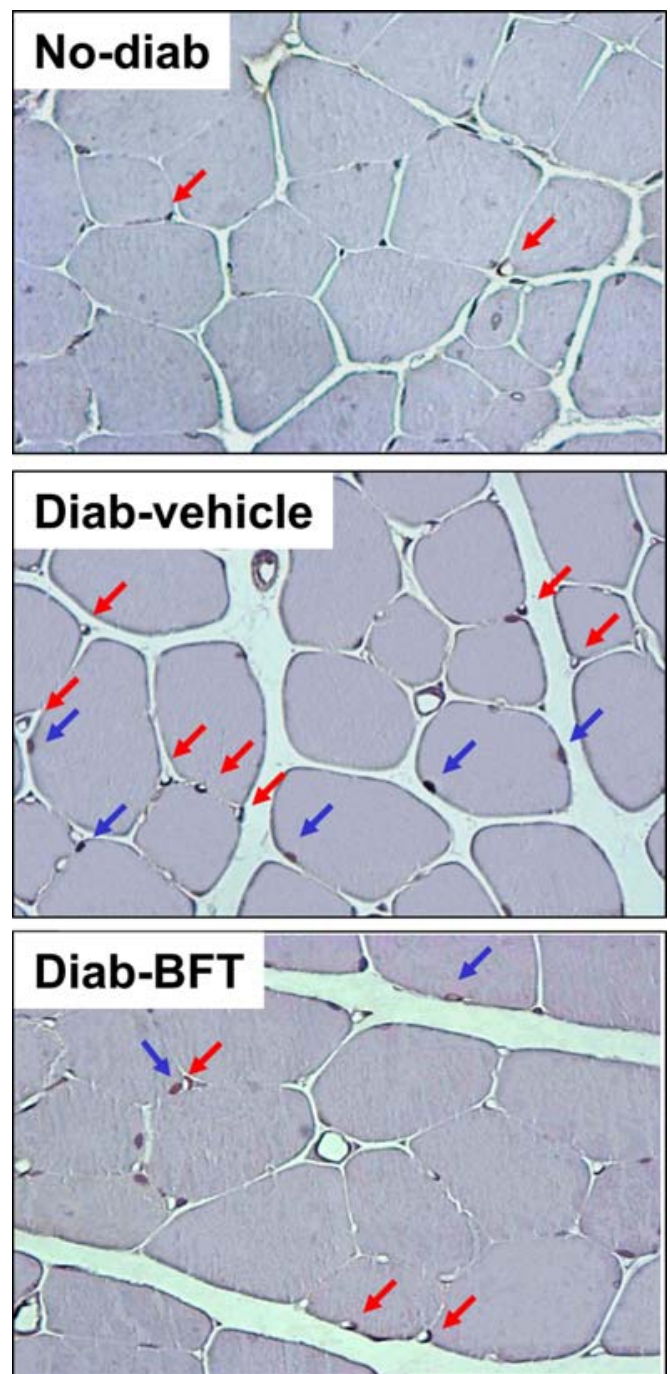

benfotiamine also significantly reduced apoptosis. c TUNEL-positive endothelial cells (red arrowheads) and myofibres (blue arrowheads) from non-diabetic controls (no-diab), diabetic mice given vehicle (diab-vehicle) and diabetic mice given benfotiamine (diab-BFT). Bar corresponds to $50 \mu \mathrm{m}$. All values are means \pm SEM; $n=6$ mice per group. The symbols are the same as for Fig. 4 
ing that the newly formed diabetic vessels are functionally incompetent.

The capillarisation of ischaemic muscles was 1.29-fold higher in benfotiamine-treated diabetic mice than in vehicle-treated mice $(p<0.01$ vs vehicle-treated diabetic mice, $n=12$ and 9 , respectively) (Fig. 4a,b). The observed improvement was partly the result of arteriogenesis (Fig. 4c). In fact, benfotiamine treatment resulted in a 1.37 -fold higher arteriole density ( $p<0.001$ vs vehicle). As a consequence, adductor vascular area was 1.40 -fold larger in benfotiamine-treated diabetic mice (Fig. $4 \mathrm{~d}, p<0.01$ vs vehicle). Similar results were obtained in the gastrocnemious muscles (data not shown). Potentiation of neovascularisation by benfotiamine accounts for restoration of resting muscular blood flow. However, the inability to dilate properly in response to acetylcholine suggests that the newly formed vascular network has a reduced reserve capacity.
Benfotiamine reduces ischaemia-induced apoptosis in the diabetic limb

Endothelial cell (Fig. 5a) and myocyte (Fig. 5b) apoptosis was increased by diabetes, with an additional increment following ischaemia in mice given vehicle ( $p<0.05$ vs nondiabetic mice; $n=6$ animals per group). The number of TUNEL-positive endothelial cells in ischaemic muscles was 2.24-fold less in benfotiamine-treated diabetic mice as compared with the number in vehicle-treated mice $(n=6$; $p<0.01$ vs vehicle). In addition, benfotiamine reduced ischaemia-induced myofibre apoptosis in diabetic mice by 1.96 -fold ( $p<0.01$ vs vehicle). The numbers of apoptotic endothelial cells and myofibres were also diminished in contralateral muscles (1.69- and 1.32-fold, respectively; $p<0.05$ vs vehicle). The microphotographs presented in Fig. $5 \mathrm{c}$ illustrate the TUNEL staining of ischaemic muscles from diabetic and non-diabetic mice.
Fig. 6 Benfotiamine prevents high glucose-induced downregulation of phosphorylated $\mathrm{PKB} /$ Akt and stimulates nuclear translocation of phosphorylated $\mathrm{PKB} / \mathrm{Akt}$ in human endothelial cells. Immunohistochemical identification of phosphorylated PKB/Akt in HUVECs shows cytoplasmatic localisation of the kinase under normal glucose, with no difference between vehicle (a) or $150 \mu \mathrm{mol} / 1$ benfotiamine (b). Incubation in high glucose reduces levels of phosphorylated PKB/Akt

(c); however, benfotiamine partially prevents the glucoseinduced decrease in phosphorylated $\mathrm{PKB} / \mathrm{Akt}$ (d). Incubation in high glucose and low serum reduces the number of HUVECs; phosphorylated $\mathrm{PKB} / \mathrm{Akt}$ immunoreactivity is localised in the cytoplasm of surviving cells (e). Under the same conditions, benfotiamine improves the viability of HUVECs and stimulates translocation of phosphorylated PKB/Akt to the nucleus (f). Phosphorylated $\mathrm{PKB} /$ Akt localisation was revealed using fluorescein-conjugated antibodies (green) Counterstaining of nuclei was performed using Hoechst (blue)
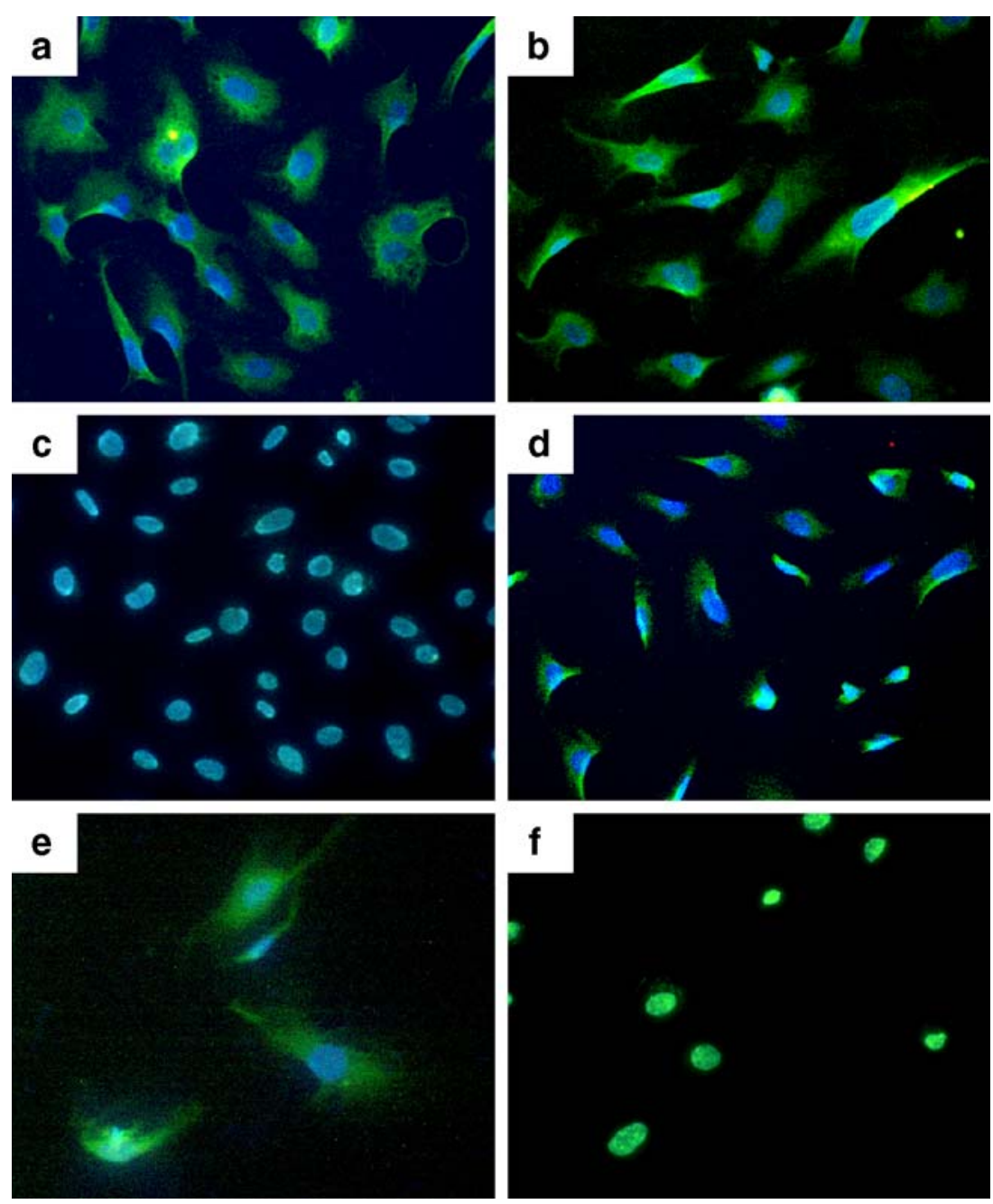
Benfotiamine activates transketolase in diabetic muscles

In hindlimb muscles of vehicle-treated diabetic mice, transketolase activity was reduced $(3.2 \pm 0.3$ vs $6.2 \pm 0.4 \mathrm{nmol}$ $\min ^{-1} \mathrm{mg}^{-1}$ protein for non-diabetic mice, $p<0.05$ ). Benfotiamine treatment of diabetic mice restored physiological levels of transketolase activity $\left(5.8-0.3 \mathrm{nmol} \mathrm{min}{ }^{-1} \mathrm{mg}^{-1}\right.$ protein, $p=\mathrm{NS}$ vs non-diabetic mice).

\section{Mechanisms of vascular protection}

\section{Activation of PKB/Akt}

We first tested the expression of Ser473-phosphorylated $\mathrm{PKB} / \mathrm{Akt}$ in HUVECs stimulated with either benfotiamine or vehicle in glucose at different concentrations of serum. Fig. 6a shows the cytoplasmic localisation of the activated form of PKB/Akt under normal glucose, and Fig. 6b shows that this not changed in the presence of benfotiamine. We found that high glucose reduces the immunoreactivity of Ser473-phosphorylated PKB/Akt (Fig. 6c), and that benfotiamine blocks this effect (Fig. 6d). Under conditions of low serum and high glucose, benfotiamine supplementation led to exclusive nuclear localisation of Ser473-phosphorylated PKB/Akt (Fig. 6f).

The activation state of $\mathrm{PKB} / \mathrm{Akt}$ was evaluated in ischaemic muscles of diabetic and non-diabetic muscles by western blot analysis of tissue homogenates (Fig. 7a) and imunohistochemistry (Fig. 7b). Results indicate that diabetes reduces the levels of phosphorylated $\mathrm{PKB} / \mathrm{Akt}$ in muscles ( $p<0.05$ vs non-diabetic mice), with this alteration being corrected by benfotiamine.

We found that benfotiamine-induced angiogenesis $\left(1,112 \pm 36\right.$ capillaries $\left./ \mathrm{mm}^{2}\right)$ and arteriogenesis $(31 \pm 3$ arterioles/section) were significantly inhibited by intramuscular Ad.DN-PKB/Akt (759 \pm 25 capillaries $/ \mathrm{mm}^{2}$ and
Fig. 7 Benfotiamine upregulates the activated form of $\mathrm{PKB} / \mathrm{Akt}$ in diabetic muscles. ai Representative western blots of phosphorylated $\mathrm{PKB} / \mathrm{Akt}$, total PKB/Akt and tubulin in ischaemic skeletal muscles from diabetic (given vehicle or benfotiamine $[B F T]$ ) and nondiabetic mice. ii, iii Bar graphs to show the ratio of phosphorylated Akt:Akt (ii) and the ratio of phosphorylated Akt:tubulin (iii), calculated from the western blots. Values are means \pm SEM; $n=6$ mice per group. ${ }^{+} p<0.05$ vs non-diabetic mice, $* p<0.05$ vs vehicle-treated diabetic mice. b Immunohistochemical identification of phosphorylated $\mathrm{PKB} / \mathrm{Akt}$ revealed by 3-amino-9-ethylcarbazole (red staining) in adductor muscle sections from non-diabetic and vehicle- or benfotiaminetreated diabetic mice subjected to unilateral limb ischaemia. The immunoreactivity for phosphorylated $\mathrm{PKB} / \mathrm{Akt}$ is reduced in diabetic muscles, but not in the presence of benfotiamine

\section{ai}
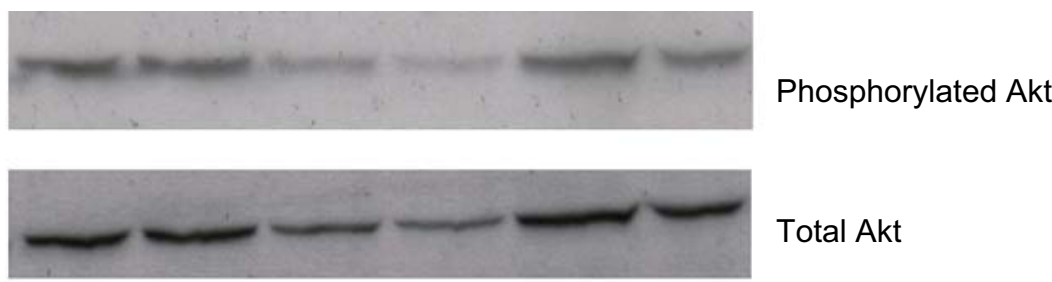

Total Akt

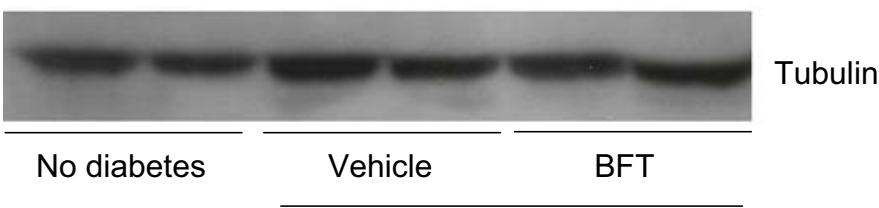

Diabetes ii

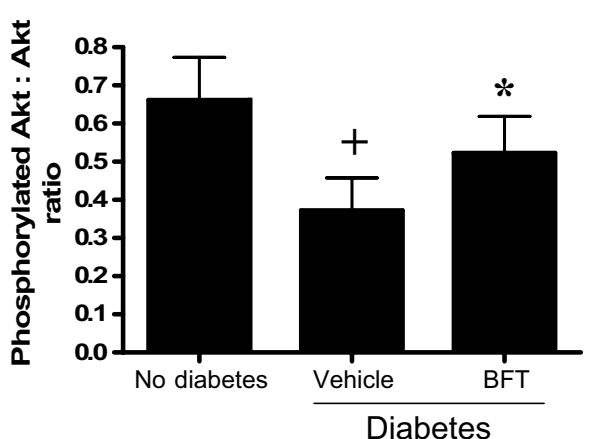

b

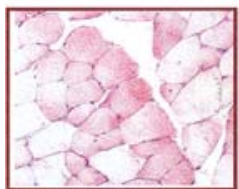

No diabetes

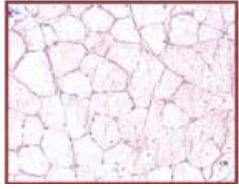

Vehicle
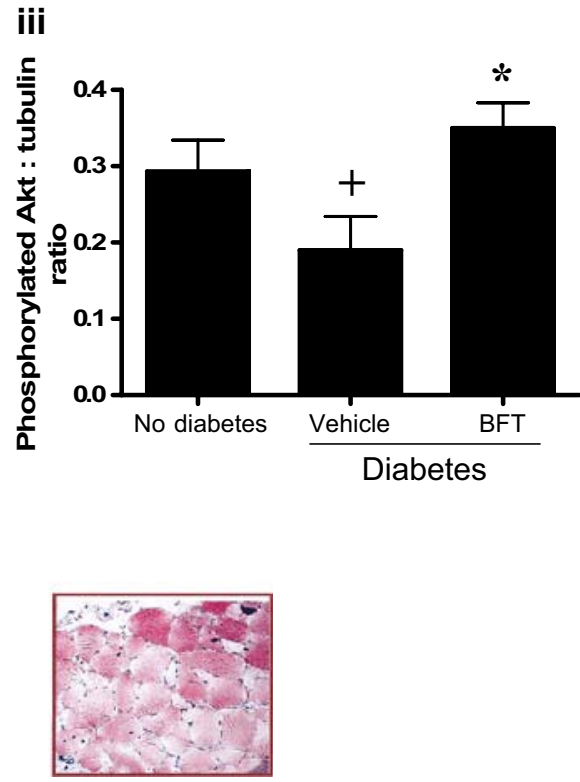

BFT
Diabetes 
$22 \pm 3$ arterioles/section, respectively, $n=8$ per group, $p<0.01)$. Thus, the densities of capillaries and arterioles in ischaemic muscles of Ad.DN-PKB/Akt-injected, benfotiamine-treated mice did not differ from those observed in the diabetic vehicle-administered mice. Similarly, the anti-apoptotic effect of benfotiamine was inhibited by Ad.DN-PKB/Akt (data not shown).

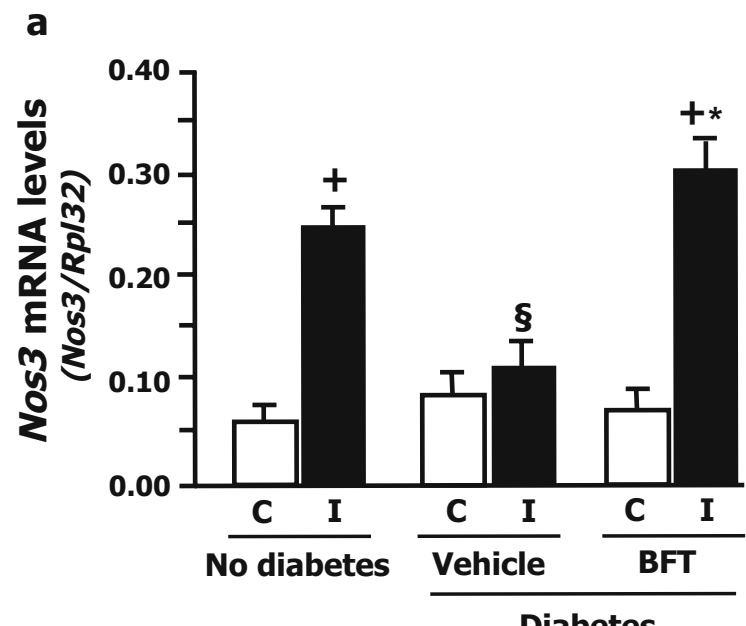

b

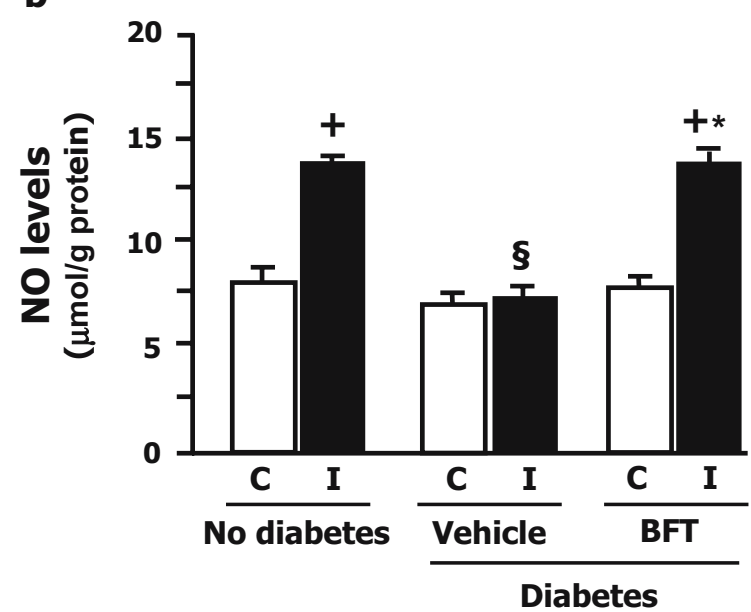

Fig. 8 Benfotiamine restores Nos3 mRNA levels in diabetic adductor muscles subjected to ischaemia. a The bar graph shows the results of quantitative real-time PCR analysis of Nos 3 expression. In non-diabetic mice $(n=5)$, ischaemia $(I)$ causes a 3.2 -fold increase in the expression of muscular Nos 3 mRNA, as compared with contralateral $(\mathrm{C})$ muscles. In contrast, untreated diabetic mice $(n=9)$ did not show any change in Nos 3 mRNA levels following ischaemia. Nos 3 expression is not reduced in benfotiamine-treated (BFT) diabetic mice $(n=10)$. Quantitative real-time PCR analysis was performed on muscles harvested 3 days after ischaemia induction and Nos3 was normalised to Rpl32 mRNA levels. b The bar graph shows NO levels in muscles from diabetic and nondiabetic mice. Benfotiamine treatment restored upregulation of $\mathrm{NO}$ release in ischaemic diabetic muscles. Values are means \pm SEM. ${ }^{+} p<0.05$ vs contralateral muscle, ${ }^{\S} p<0.05$ vs non-diabetic mice, ${ }^{*} p<0.05$ vs vehicle-treated diabetic mice. I Ischaemic muscle, $C$ contralateral muscle
Modulation of Nos 3 expression and NO production in ischaemic muscles

Figure 8a illustrates the effects of diabetes and ischaemia on Nos 3 expression normalised to Rpl32. In non-diabetic mice $(n=5)$, interruption of femoral blood-flow resulted in higher expression of muscular Nos 3 mRNA levels $(p<0.05$ vs contralateral). In contrast, Nos 3 expression remained unchanged in untreated diabetic mice $(n=9, p=\mathrm{NS}$ vs contralateral). In benfotiamine-treated diabetic animals $(n=10)$, Nos 3 expression was increased $(p<0.05$ vs vehicle-treated diabetic mice) such that it matched the levels observed in non-diabetic animals.

As shown in Fig. 8b, NO content was increased after induction of ischaemia in muscles of non-diabetic mice ( $n=8, p<0.01$ vs contralateral), whereas this response was absent in muscles of diabetic animals $(n=8, p=\mathrm{NS}$ vs contralateral). NO upregulation occurred in ischaemic muscles of benfotiamine-treated mice, the NO content in these muscles being 1.7-fold higher as compared with the content in the contralateral muscles $(n=8 ; p<0.01)$. Vegfa mRNA levels did not differ in ischaemic limb muscles of diabetic mice given benfotiamine or vehicle (data not shown).

\section{Inhibition of Casp3 expression}

Quantitative real-time PCR analysis of Casp3 mRNA levels (Fig. 9a) indicated upregulation of the apoptosis effector in ischaemic muscles of untreated diabetic $(n=6)$ or non-diabetic mice $(n=4) \quad(p<0.05$ vs contralateral). In benfotiamine-treated diabetic mice $(n=6)$, Casp 3 expression was 7.5 -fold lower as compared with that in vehicletreated diabetic mice or non-diabetic mice $(p<0.05$ for both).

Western blot analysis of activated caspase-3 (Fig. 9b) showed 2.9- and 2.7-fold lower protein levels in ischaemic muscles of benfotiamine-treated diabetic mice as compared with those in vehicle-treated diabetic mice or non-diabetic mice ( $n=6$ muscles per group, $p<0.05$ for both comparisons).

\section{AGE inhibition}

As illustrated in Fig. 10, AGE content was enhanced in the vascular endothelium of untreated diabetic mice $(n=4)$. This effect was prevented by benfotiamine $(0.5 \pm 0.2$ vs 2.0 \pm 0.17 AGE-positive endothelial cells per carotid artery section in vehicle, $p<0.05, n=4)$.

\section{Effects on oxidative stress}

In diabetic mice, the GSH content of the aortic tissue $(1.45 \pm 0.14 \mathrm{nmol} / \mathrm{mg}$ protein) was lower than that in nondiabetic mice $(4.69 \pm 0.15 \mathrm{nmol} / \mathrm{mg}$ protein, $p<0.01)$. Benfotiamine-treated diabetic mice showed a modest increase in aortic tissue GSH content $(1.70 \pm 0.15 \mathrm{nmol} / \mathrm{mg}$ 
protein), but this value did not differ significantly from that of vehicle-treated diabetic mice. As regards the GSSG content of the aorta, there was no difference between the vehicle-treated diabetic mice $(0.21 \pm 0.04 \mathrm{nmol} / \mathrm{mg}$ protein $)$ the benfotiamine-treated diabetic mice $(0.16 \pm 0.03 \mathrm{nmol} /$ $\mathrm{mg}$ protein $)$ and the non-diabetic controls $(0.13 \pm 0.06 \mathrm{nmol} /$ $\mathrm{mg}$ protein). As a consequence of these changes, the GSH: GSSG ratio was significantly lower in the diabetic than in the control aortas $(6.1 \pm 0.2$ vs $41.0 \pm 9.3, p<0.01)$, with no effect of benfotiamine $(9.3 \pm 0.5, p=\mathrm{NS})$.

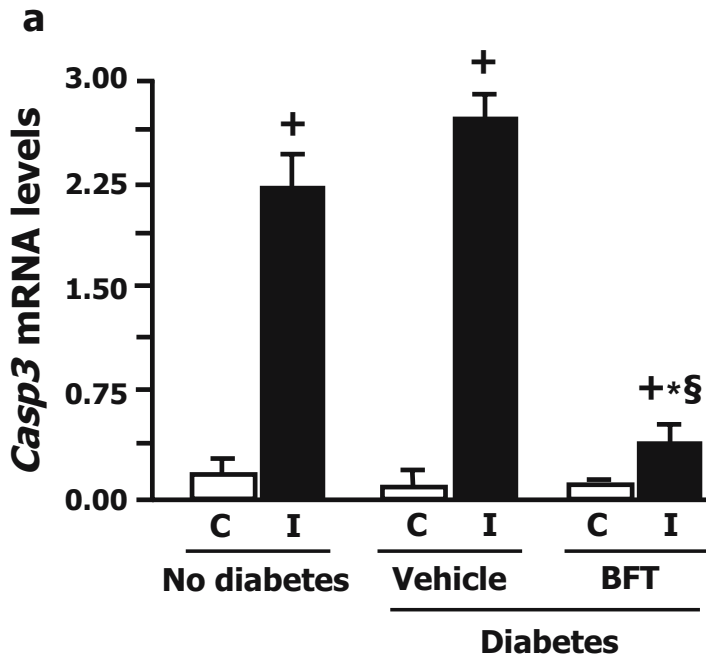

b

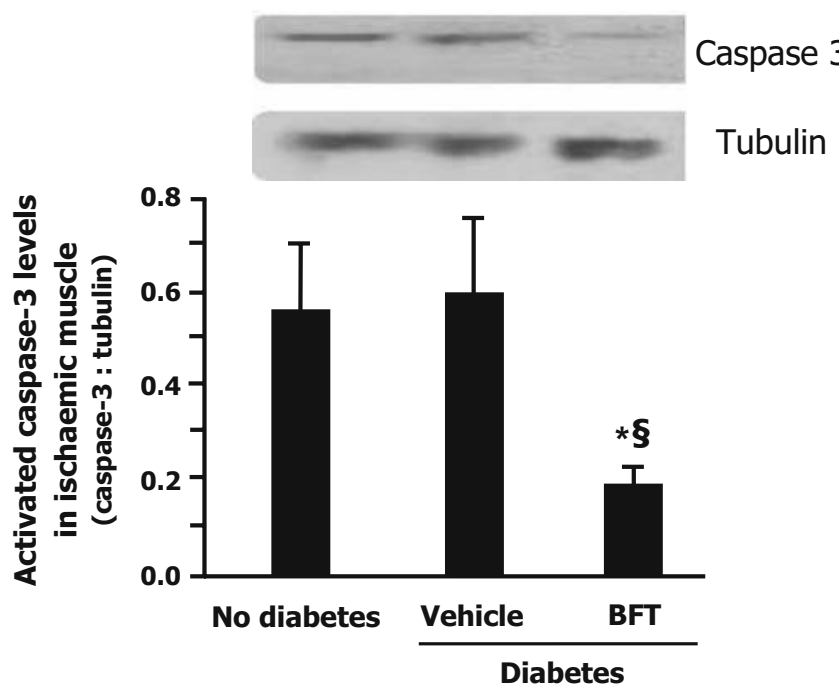

Fig. 9 Benfotiamine prevents ischaemia-induced upregulation of Casp3. a Bar graph shows the results of quantitative real-time PCR analysis of Casp3 expression. Benfotiamine significantly reduces the ischaemia-induced increase in muscular Casp3 mRNA. Values were normalised against Rpl32 mRNA levels. b Bar graph shows results of western blot analysis of activated caspase-3 in ischaemic skeletal muscles from diabetic and non-diabetic mice. Benfotiamine significantly reduced the ischaemia-induced increase in activated caspase-3. Representative blots are shown above the graph. Values are means \pm SEM; $n=4-6$ mice per group. ${ }^{+} p<0.05$ vs contralateral muscle, ${ }^{\S} p<0.05$ vs non-diabetic mice, ${ }^{*} p<0.05$ vs vehicle-treated diabetic mice. $I$ Ischaemic muscle, $C$ contralateral muscle
Benfotiamine stimulates proliferation and inhibits apoptosis of cultured human EPCs

As shown in Fig. 11a, benfotiamine stimulates EPC proliferation under high or physiological glucose conditions. The proliferative effect, however, was blunted by reduced serum concentration ( $2 \%$ serum) (data not shown).

In addition, benfotiamine improved EPC viability. As shown in Fig. 11b, the apoptosis rate of EPCs averaged $7.0 \pm 2.1 \%$ in the presence of high glucose and $2 \%$ serum, and averaged $0.2 \pm 0.1 \%$ in the presence of normal glucose and $5 \%$ serum $(p<0.01)$. Benfotiamine was able to prevent the apoptosis induced by high glucose and $2 \%$ serum $(1.1 \pm 0.7 \%$ apoptotic EPCs, $p<0.01)$.
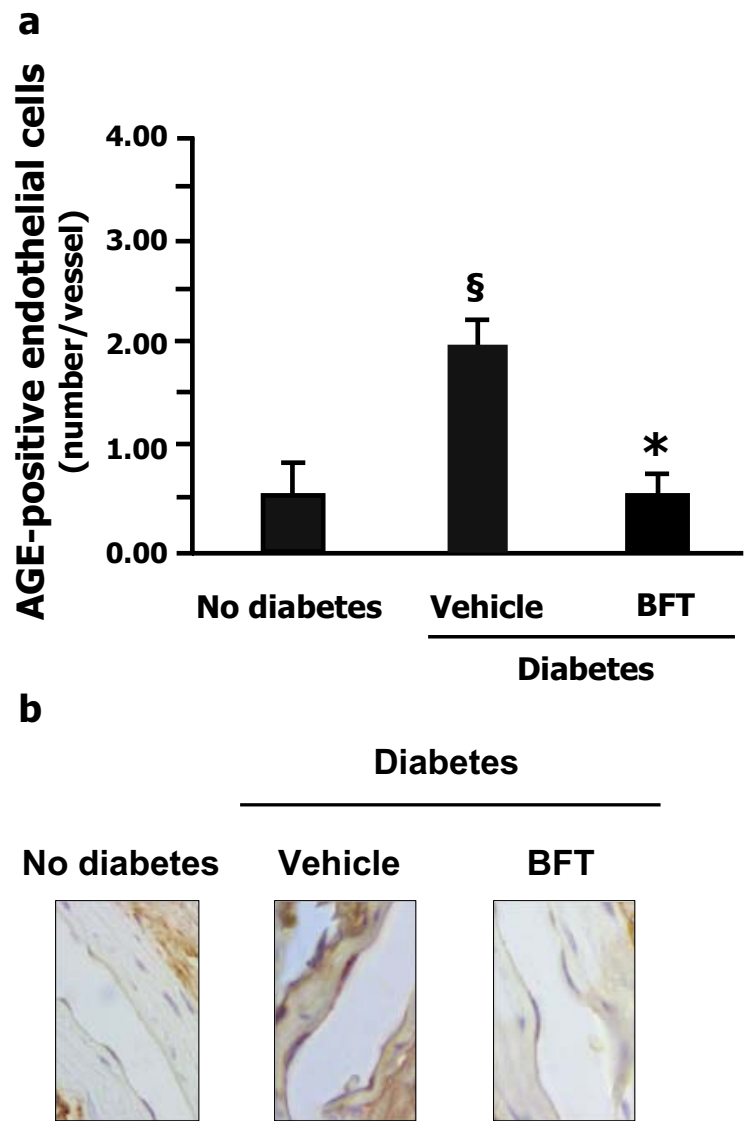

Fig. 10 Benfotiamine prevents diabetes-induced AGE accumulation in arterial endothelium. a The bar graph shows the number of AGE-positive endothelial cells per section of carotid artery from diabetic and non-diabetic mice ( $n=4$ mice per group). Benfotiamine (BFT) reduced AGE immunostaining in vascular endothelium of diabetic mice. Values are means \pm SEM. ${ }^{\S} p<0.05$ vs non-diabetic mice, ${ }^{*} p<0.05$ vs vehicle-treated diabetic mice. b Microphotographs show immunohistochemical evidence of diabetes-induced AGE accumulation in carotid artery endothelial cells. AGE accumulation was prevented by benfotiamine such that the number of AGEpositive cells was similar to that observed in non-diabetic vessels. AGE-positive cells are stained in brown 
Fig. 11 Benfotiamine stimulates the proliferation and inhibits the apoptosis of human EPCs cultured under high-glucose conditions and increases the number of circulating murine EPCs. a The bar graph shows the results of the proliferation assay performed with human EPCs incubated with increasing concentrations of benfotiamine (BFT) or vehicle, physiological or high glucose, and 5\% FBS. At concentrations of 100 and $150 \mu \mathrm{mol} / 1$ benfotiamine significantly increases the rate of proliferation of the EPCs in the presence of a $5 \%$ serum concentration. However, the proliferative effect was blunted in the presence of a low concentration of serum (data not shown). ${ }^{*} p<0.05$ vs 0 b The bar graph shows the apoptotic rate of human EPCs incubated in normal glucose and 5\% serum (left) or high glucose and $2 \%$ serum (right). Apoptosis induced by high glucose and serum deprivation was reduced by benfotiamine. Values are means \pm SEM of 10 wells. ${ }^{*} p<0.05$ vs 0 benfotiamine. c The bar graph shows the number of circulating EPCs in diabetic and nondiabetic mice (upper panel). Values are means \pm SEM and indicate the number of cells per microscopic field. ${ }^{*} p<0.05$ vs non-diabetic mice. Typical microphotographs (lower panel) show double-fluorescence immunohistochemistry of murine EPCs

a

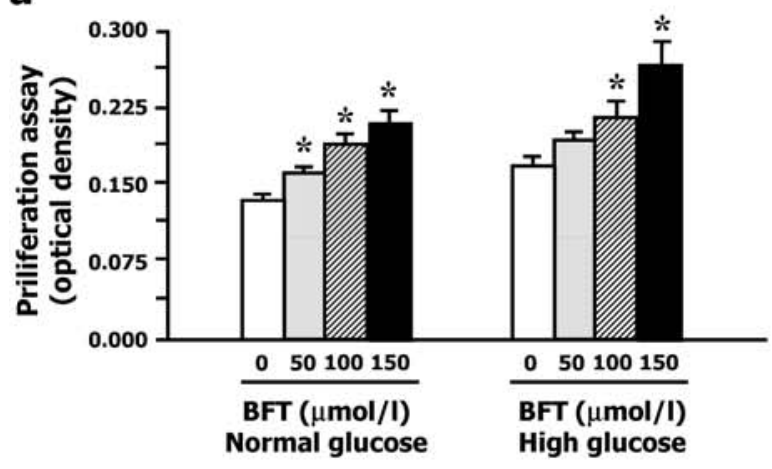

b

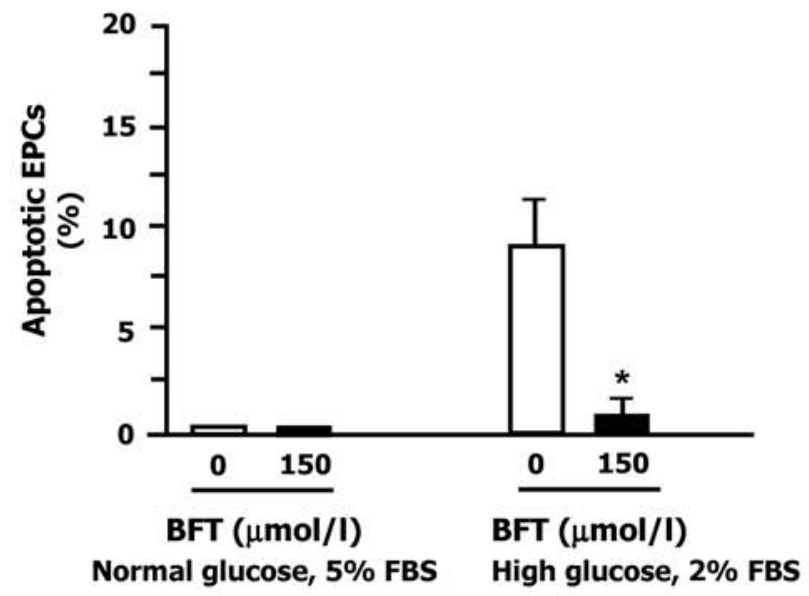

C

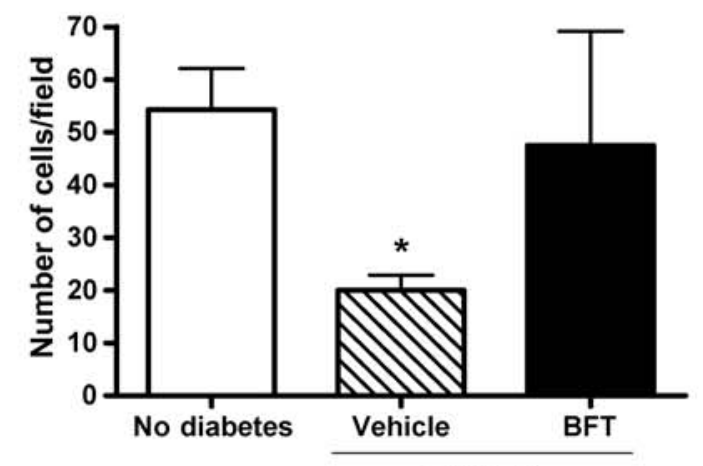

Diabetes

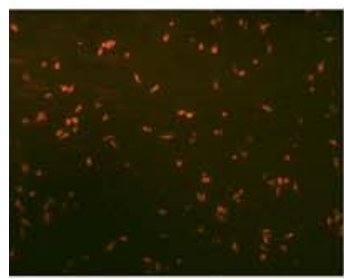

No diabetes

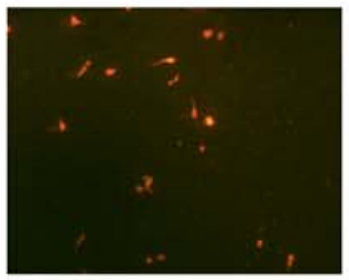

Vehicle

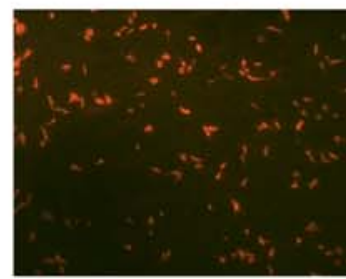

BFT

\section{Diabetes}


Benfotiamine increases the number of circulating EPCs

In diabetic mice submitted to limb ischaemia (Fig. 11c), the number of circulating EPCs was half the number observed in non-diabetic mice $(p<0.05)$, with this effect prevented by benfotiamine. Fig. 11c (lower panels) shows typical fluorescent microscopy microphotographs of Dil-AcLDL/ lectin positive cells from diabetic and non-diabetic mice.

\section{Discussion}

The present study is, to our knowledge, the first to report that benfotiamine supplementation improves the postischaemic healing of diabetic mice through stimulation of reparative angiogenesis and inhibition of apoptosis, and demonstrates that these therapeutic effects are mediated by activation of $\mathrm{PKB} / \mathrm{Akt}$. Furthermore, benfotiamine improves the biology of EPCs.

Mild thiamine deficiency has been found in type 1 and type 2 clinical diabetes [42-44] and in STZ-induced diabetic rats [29]. In diabetic rats, this was caused by an eight-fold increase in the renal clearance of thiamine. Both high-dose benfotiamine and thiamine corrected the thiamine deficiency in STZ-induced diabetic rats, and also corrected the increase in renal clearance of thiamine [29]. Thiamine is the cofactor of transketolase, the enzyme that diverts glucose metabolites towards pentoses, which are less toxic to endothelial cells. As a consequence of this, thiamine deficiency may result in reduced transketolase activity, thus exacerbating the consequences of chronic hyperglycaemia. Accordingly, we found that transketolase activity is reduced in skeletal muscles of diabetic mice, with this deficit being restored to normal by oral supplementation with benfotiamine. Similarly, benfotiamine reportedly activates transketolase in bovine endothelial cells and normalises enzymatic activity in mouse diabetic retinas [30]. Furthermore, high doses of thiamine and benfotiamine may reverse decreased glomerular transketolase activity in diabetic rats by two distinct mechanisms: augmentation of cofactor availability and induction of transketolase expression [29]. Collectively, these results indicate that benfotiamine supplementation can restore the physiological function of transketolase in different tissues of type 1 diabetic animals.

Experimental evidence supports a therapeutic role for agents targeting single pathways of hyperglycaemia-induced microvascular damage, including inhibitors of PKC- $\beta$ [45] or AGEs [46]. Benfotiamine may surpass these agents, as it exerts global control of the different mechanisms implicated in the pathogenesis of diabetic endotheliopathy. In fact, recent studies indicate that thiamine and benfotiamine inhibit the diacylglycerol-PKC, hexosamine and polyol pathways and AGE formation, thereby preventing incipient nephropathy and retinopathy $[29,30]$. This information prompted us to test the hypothesis that the microvascular protection afforded by benfotiamine could include peripheral ischaemia.
In vehicle-treated diabetic mice, we found a high occurrence of toe necrosis and delayed recovery of limb perfusion following interruption of femoral blood flow. Accordingly, limb ischaemia has a severe course in diabetic patients, often resulting in foot ulceration and lower extremity amputation [3, 4]. The poor outcome is seemingly related to a diminished ability to develop collateral vessels $[6-8,47]$. In the present study we did not detect a significant reduction in the capillary or arteriole densities of ischaemic diabetic muscles as compared with non-diabetic controls. However, haemodynamic data indicate that diabetic neovascularisation was not sufficient for adequate perfusion/oxygenation under resting conditions and was unresponsive to the endothelium-dependent vasodilator acetylcholine.

One major novel finding of the present study is that benfotiamine supplementation prior to and following the induction of ischaemia resulted in significant improvements in clinical, functional and histological endpoints. Benfotiamine-treated diabetic mice showed reduced toe necrosis compared with vehicle-treated diabetic mice, and regained normal levels of perfusion in operated adductors within 2 weeks. Furthermore, benfotiamine enabled diabetic muscles to respond to the ischaemic insult with enhanced formation of new capillaries and arterioles as compared with untreated diabetic ones, thereby resulting in enlarged vascular area per unit of muscular section and improved resting blood flow. Endothelial dysfunction, however, was not fully corrected by benfotiamine, which might leave diabetic muscles underperfused under conditions of increased metabolic demand or exercise.

In the attempt to elucidate the mechanisms responsible for vascular protection, we focused on oxidative stress and AGEs that are important mediators of diabetes-induced cellular damage. In vitro and in vivo studies indicate that thiamine [48] and benfotiamine [29] have antioxidant properties, notwithstanding the report that benfotiamine has no effect on ROS accumulation induced by high glucose [30], which is in keeping with results obtained by us using human endothelial cells (P. Madeddu, unpublished observations). In addition, we found that benfotiamine supplementation did not restore the reduced GSH:GSSG ratio in diabetic mice. In another study on diabetic rats [29], levels of plasma protein thiols were decreased, suggesting activation of oxidative stress in these animals. Interestingly, the decrease was prevented by $70 \mathrm{mg} / \mathrm{kg}$ benfotiamine, whereas a ten-fold lower dosage was ineffective. Because the latter dose prevented the development of proteinuria in diabetic rats, it was concluded that renal protection by benfotiamine does not obligatorily require the suppression of oxidative stress [29]. Taken together, these studies suggest that benfotiamine might exert vascular and renal benefits by modulating mechanisms independent or downstream of ROS formation. For example, AGEs could disturb reparative neovascularisation through transcriptional and post-transcriptional inactivation of modulators of angiogenesis. Accordingly, we report here that oral benfotiamine administration prevents AGE accumulation in vascular endothelium of diabetic mice. Interpretation of our 
immunohistochemical studies deserves a cautionary comment. In fact, even though samples were processed identically for the two groups of diabetic mice, it is still possible for artefacts to occur as a result of AGE formation promoted by heating and hydrogen peroxide during sample processing [49]. Hence, benfotiamine samples might be less susceptible to AGE formation from fructosyl lysine. It should be noted, however, that, in line with our results, markers of protein glycation are reportedly reduced by benfotiamine in diabetic retinas [30] and renal glomeruli [29].

Importantly, we newly demonstrate that benfotiamine benefits the diabetic vasculature via a mechanism involving the activation of $\mathrm{PKB} / \mathrm{Akt}$. This assertion is supported by the following results: (1) in cultured human endothelial cells, benfotiamine prevents the high glucose-induced decrease in Ser473-phosphorylated PKB/Akt and induces the nuclear localisation of active $\mathrm{PKB} / \mathrm{Akt}$, which reportedly leads to phosphorylation of transcription factors that are implicated in the control of cell survival [50]; (2) in vivo, benfotiamine supplementation prevents the diabetesinduced reduction of activated $\mathrm{PKB} / \mathrm{Akt}$ protein production in diabetic ischaemic muscles; (3) the in vivo pro-angiogenic and anti-apoptotic action of benfotiamine is not observed following inhibition of $\mathrm{PKB} / \mathrm{Akt}$ with intramuscular Ad.DN-PKB/Akt; (4) benfotiamine supplementation restores the expression of Nos 3 and the release of $\mathrm{NO}$ in ischaemic diabetic muscles.

The protein kinase PKB/Akt plays a central role in the control of angiogenesis and endothelial cell homeostasis. Activation of $\mathrm{PKB} / \mathrm{Akt}$ promotes endothelial cell survival by inhibiting apoptosis [24], stimulates endothelial NO synthesis [25], and mediates the vascular effects of different growth factors [24-26]. Recent studies have demonstrated that the phosphoinositide-3-kinase-PKB/ Akt-eNOS pathway inhibits apoptosis by post-translational modifications of pro-apoptotic proteins such as Bad and caspase- 3 and by induction of the expression of the antiapoptotic proteins survivin and Bcl-2 [51]. Furthermore, nuclear translocation of phospho-PKB/Akt is followed by phosphorylation/inactivation of forkhead transcription factors, which control EC viability through activation of the extrinsic apoptotic pathway [52]. We found that, under conditions of high glucose/low serum, benfotiamine protects human endothelial cells from apoptosis, an effect associated with nuclear translocation of phosphorylatedPKB/Akt. Furthermore, we observed that benfotiamine inhibits the induction of activated caspase- 3 in ischaemic muscles. Importantly, the anti-apoptotic effect of benfotiamine was blocked by intramuscular Ad.DN-PKB/Akt, thus favouring a role for the kinase in benfotiamine's prosurvival action. A complementary protection against myofibre apoptosis could be derived from improved perfusion and oxygenation of ischaemic limbs in benfotiaminetreated mice.

A growing body of evidence indicates that neovascularisation does not exclusively depend on resident endothelial cells but also involves bone marrow-derived circulating EPCs. Furthermore, EPC function is impaired in type I diabetic patients [41]. Results of the present study indicate, for the first time, that under HG conditions, benfotiamine dose-dependently stimulates the proliferation of human EPCs. In addition, benfotiamine improves the viability of human EPCs exposed to high glucose and low serum. Finally, we found that the number of circulating EPCs is reduced in diabetic mice subjected to limb ischaemia and that benfotiamine supplementation corrects this decrease. These interesting findings might open new avenues for therapeutic angiogenesis/vasculogenesis. In fact, benfotiamine may correct diabetes-related liabilities in both resident endothelial cells and circulating EPCs.

\section{Conclusions and clinical implications}

The most relevant feature of benfotiamine is that oral administration of this vitamin derivative simultaneously addresses three harmful complications of diabetes: limb ischaemia (as demonstrated here), nephropathy [29] and retinopathy [30]. This sets benfotiamine apart from traditional angiogenesis therapy approaches that, although useful for treatment of peripheral ischaemia, may endanger the diabetic retina. In terms of the prevention of nephropathy, it would be of paramount importance to evaluate in future studies whether prevention of proteinuria by benfotiamine results from improvements in renal microcirculation. Lastly, like statins, which similarly stimulate angiogenesis via the PKB/Akt pathway, benfotiamine is clinically available. Thus, benfotiamine could represent the long-awaited global remedy for complications related to microvascular diabetic disease.

Acknowledgements This study was supported by grants from the Telethon-Onlus Foundation (grant no. GP0300Y01), the Juvenile Diabetes Research Foundation (grant no. 1-2004-124), the Italian Ministry of University and Research (FIRB). S. van Linthout, F. Spillmann and K. Ward were supported by a Marie Curie Fellowship of the European Community programme 'Quality of Life' under contract number HPMD-CT-2001-00074. The National Institute of Biostructures and Biosystems laboratories and Bristol University are partners of the European Genomic Vascular Network funded by the European Community.

\section{References}

1. Ouriel K (2001) Peripheral arterial disease. Lancet 358:12571264

2. Hiatt WR (2001) Medical treatment of peripheral arterial disease and claudication. N Engl J Med 344:1608-1621

3. Currie CJ, Morgan CL, Peters JR (1998) The epidemiology and cost of inpatient care for peripheral vascular disease, infection, neuropathy, and ulceration in diabetes. Diabetes Care 21:42-48

4. Humphrey LL, Palumbo PJ, Butters MA et al (1994) The contribution of non-insulin-dependent diabetes to lower-extremity amputation in the community. Arch Intern Med 154:885-892 
5. Regensteiner JG, Hiatt WR (2002) Current medical therapies for patients with peripheral arterial disease: a critical review. Am J Med 112:4957

6. Rivard A, Silver M, Chen D et al (1999) Rescue of diabetesrelated impairment of angiogenesis by intramuscular gene therapy with adeno-VEGF. Am J Pathol 154:355-363

7. Taniyama Y, Morishita R, Hiraoka K et al (2001) Therapeutic angiogenesis induced by human hepatocyte growth factor gene in rat diabetic hind limb ischemia model: molecular mechanisms of delayed angiogenesis in diabetes. Circulation 104: 2344-2350

8. Emanueli C, Graiani G, Salis MB, Gadau S, Desortes E, Madeddu P (2004) Prophylactic gene therapy with human tissue kallikrein ameliorates limb ischemia recovery in type 1 diabetic mice. Diabetes 53:1096-1103

9. Lederman RJ, Mendelsohn FO, Anderson RD et al (2002) Therapeutic angiogenesis with recombinant fibroblast growth factor-2 for intermittent claudication (the TRAFFIC study): a randomised trial. Lancet 359:2053-2058

10. Rajagopalan S, Mohler ER 3rd, Lederman RJ et al (2003) Regional angiogenesis with vascular endothelial growth factor in peripheral arterial disease: a phase II randomized, doubleblind, controlled study of adenoviral delivery of vascular endothelial growth factor 121 in patients with disabling intermittent claudication. Circulation 108:1933-1938

11. Simons M (2005) Angiogenesis. Where do we stand now? Circulation 111:1556-1566

12. The DCCT Research Group (1993) The effect of intensive treatment of diabetes on the development and progression of long-term complications in insulin-dependent diabetes mellitus. N Engl J Med 329:977-986

13. UK Prospective Diabetes Study (UKPDS) Group (1998) Intensive blood-glucose control with sulphonylureas or insulin compared with conventional treatment and risk of complications in patients with type 2 diabetes (UKPDS 33). Lancet 352:837-853

14. Wei M, Gaskill SP, Haffner SM, Stern MP (1998) Effects of diabetes and level of glycemia on all-cause and cardiovascular mortality. The San Antonio Heart Study. Diabetes Care 21:1167-1172

15. Ushio-Fukai M, Tang Y, Fukai T et al (2002) Novel role of gp91(phox)-containing NAD(P)H oxidase in vascular endothelial growth factor-induced signaling and angiogenesis. Circ Res 91:1160-1167

16. Tojo T, Ushio-Fukai M, Yamaoka M, Ikeda S, Patrshev N, Alexander W (2005) Role of gp91phox (Nox2)-containing $\mathrm{NAD}(\mathrm{P}) \mathrm{H}$ oxidase in angiogenesis in response to hindlimb ischemia. Circulation 111:2347-2355

17. Griendling KK, Sorescu D, Ushio-Fukai M (2000) NAD(P)H oxidase. Role in cardiovascular biology and disease. Circ Res 86:494-501

18. Brownlee M (2001) Biochemistry and molecular cell biology of diabetic complications. Nature 414:813-820

19. McClain DA, Paterson AJ, Roos MD, Wei X, Kudlow JE (1992) Glucose and glucosamine regulate growth factor gene expression in vascular smooth muscle cells. Proc Natl Acad Sci U S A 89:8150-8154

20. Giardino I, Edelstein D, Brownlee M (1994) Nonenzymatic glycosylation in vitro and in bovine endothelial cells alters basic fibroblast growth factor activity. A model for intracellular glycosylation in diabetes. J Clin Invest 94:110-117

21. Schmidt AM, Hori O, Chen JX et al (1995) Advanced glycation endproducts interacting with their endothelial receptor induce expression of vascular cell adhesion molecule-1 (VCAM-1) in cultured human endothelial cells and in mice. A potential mechanism for the accelerated vasculopathy of diabetes. J Clin Invest 96:1395-1403

22. Du XL, Edelstein D, Dimmeler S, Ju Q, Sui C, Brownlee M (2001) Hyperglycemia inhibits endothelial nitric oxide synthase activity by posttranslational modification at the Akt site. J Clin Invest 108:1341-1348
23. Cai S, Khoo J, Channon KM (2005) Augmented BH4 by gene transfer restores nitric oxide synthase function in hyperglycemic human endothelial cells. Cardiovasc Res 65:823-831

24. Gerber HP, McMurtrey A, Kowalski J et al (1998) Vascular endothelial growth factor regulates endothelial cell survival through the phosphatidylinositol 3'-kinase/Akt signal transduction pathway. Requirement for Flk-1/KDR activation. J Biol Chem 273:30336-30343

25. Dimmeler S, Fisslthaler B, Fleming I, Hermann C, Busse R, Zeiher AM (1999) Activation of nitric oxide synthase in endothelial cells via Akt-dependent phosphorylation. Nature 399:601-605

26. Kim I, Kim HG, So J-N et al (2000) Angiopoietin-1 regulates endothelial cell survival through the phosphatidylinositol 3'kinase/Akt signal transduction pathway. Circ Res 86:24-29

27. Krankel N, Adams V, Linke A et al (2005) Hyperglycemia reduces survival and impairs function of circulating bloodderived progenitor cells. Arterioscler Thromb Vasc Biol 25:698-703

28. Dimmeler S, Aiche A, Vasa M et al (2001) HMG-CoA reductase inhibitors (statins) increase endothelial progenitor cells via the PI3-kinase/Akt pathway. J Clin Invest 108:391397

29. Babaei-Jadidi R, Karachalias N, Ahmed N, Battah S, Thornalley PJ (2003) Prevention of incipient diabetic nephropathy by high-dose thiamine and benfotiamine. Diabetes 52 : $2110-2120$

30. Hammes HP, Du X, Edelstein D et al (2003) Benfotiamine blocks three major pathways of hyperglycemic damage and prevents experimental diabetic retinopathy. Nat Med 9:294-299

31. Shindo H, Okamoto K, Totsu J (1967) Transport of organic compounds through biological membranes. I. Accumulative uptake of $S$-benzoylthiamine by human erythrocytes. Chem Pharm Bull (Tokyo) 15:295-302

32. Ziems M, Netzel M, Bitsch I (2000) Biokinetic parameters and metabolism of $S$-benzoylthiamine- $O$-monophosphate. Biofactors 11:109-110

33. Emanueli C, Maestri R, Corradi D et al (1999) Dilated and failing cardiomyopathy in bradykinin B2 receptor knockout mice. Circulation 100:2359-2365

34. Emanueli C, Minasi A, Zacheo A et al (2001) Local delivery of human tissue kallikrein gene accelerates spontaneous angiogenesis in mouse model of hindlimb ischemia. Circulation 103:125-132

35. Condorelli G, Drusco A, Stassi et al (2002) Akt induces enhanced myocardial contractility and cell size in vivo in transgenic mice. Proc Natl Acad Sci U S A 99:12333-12338

36. Horiuchi S, Araki N, Morino Y (1991) Immunochemical approach to characterize advanced glycation end products of the Maillard reaction: evidence for the presence of a common structure. J Biol Chem 266:7329-7332

37. Kaji Y, Usui T, Oshika T et al (2000) Advanced glycation end products in diabetic corneas. Invest Ophthalmol Vis Sci 41:362-368

38. Chamberlain BR, Buttery JE, Pannall PR (1996) A stable reagent mixture for the whole blood transketolase assay. Ann Clin Biochem 33:352-354

39. Emanueli C, Salis MB, Van Linthout S et al (2004) Akt/protein kinase $\mathrm{B}$ and endothelial nitric oxide synthase mediate muscular neovascularization induced by tissue kallikrein gene transfer. Circulation 110:1638-1644

40. Tepper OM, Galiano RD, Capla JM et al (2002) Human endothelial progenitor cells from type II diabetics exhibit impaired proliferation, adhesion, and incorporation into vascular structures. Circulation 106:2781-2786

41. Loomans CJ, de Koning EJ, Staal FJ et al (2004) Endothelial progenitor cell dysfunction: a novel concept in the pathogenesis of vascular complications of type 1 diabetes. Diabetes 53:195199

42. Saito N, Kimura M, Kuchiba A, Itokawa Y (1987) Blood thiamine levels in outpatients with diabetes mellitus. J Nutr Sci Vitaminol 33:421-430 
43. Havivi E, Bar On H, Reshef A, Raz I (1991) Vitamins and trace metals status in non-insulin dependent diabetes mellitus. Int J Vitam Nutr Res 61:328-333

44. Valerio G, Franzese A, Poggi V, Patrini C, Laforenza U, Tenore A (1999) Lipophilic thiamine treatment in longstanding insulindependent diabetes mellitus. Acta Diabetol 36:73-76

45. Ishii H, Jirousek MR, Koya D et al (1996) Amelioration of vascular dysfunctions in diabetic rats by an oral PKC beta inhibitor. Science 272:728-731

46. Hammes HP, Martin S, Federlin K, Geisen K, Brownlee M (1991) Aminoguanidine treatment inhibits the development of experimental diabetic retinopathy. Proc Natl Acad Sci U S A 88:11555-11558

47. Waltenberger J, Lange J, Kranz A (2000) Vascular endothelial growth factor-A-induced chemotaxis of monocytes is attenuated in patients with diabetes mellitus: A potential predictor for the individual capacity to develop collaterals. Circulation 102:185-190

48. Lukienko PI, Mel'nichenko NG, Zverninskii IV, Zabrodskaya SV (2000) Antioxidant properties of thiamine. Bull Exp Biol Med 130:874-876
49. Hayashi CM, Nagai R, Miyazaki K et al (2002) Conversion of Amadori products of the Maillard reaction to $N$-epsilon(carboxymethyl) lysine by short-term heating: possible detection of artifacts by immunohistochemistry. Lab Invest 82:795807

50. Brunet A, Bonni A, Zigmond MJ et al (1999) Akt promotes cell survival by phosphorylating and inhibiting a Forkhead transcription factor. Cell 96:857-868

51. Ohashi H, Takagi H, Oh H et al (2004) Phosphatidylinositol 3kinase/Akt regulates angiotensin II-induced inhibition of apoptosis in microvascular endothelial cells by governing survivin expression and suppression of caspase-3 activity. Circ Res 94:785-793

52. Skurk C, Maatz H, Kim HS et al (2004) The Akt-regulated forkhead transcription factor FOXO3a controls endothelial cell viability through modulation of the caspase- 8 inhibitor FLIP. J Biol Chem 279:1513-1525 